\title{
An Ecology of Innovation: Adapt, Reuse and Reimagine
}

\author{
PETER S. RAAB
}

Texas Tech University

This paper questions the role of ecology through the design of three small, but impactful projects from different political and bioclimatic regions in North America. An adobe home in the Sonoran desert of Mexico, a rope pavilion in the Texas hill country, and an ice hut in Manitoba, Canada. Each of these investigations reveal site-specific ecologies to determine interventions rooted in local cultural and biological systems. The three solutions probe dis-global networks using unique environmental foci in the hopes of transferring knowledge of how ecology, architectural design and material construction may deal with the abstract nature of ecology in tangible terms. These diverse, ecologically sensitive and material specific solutions belie the premise of singular solutions for all ecologies, but insist on sharing singular explorations employed to fully nest design ideations within the local environs by balancing culture, site, ecological and programmatic issues.

\section{DWELLING WITH NATURE}

Likely one of the first dwellings man resided after the caves, was earthen. Even today, tens of thousands of years later, approximately thirty percent of the world's population lives in earthen structures.' While the soil components and technological means of these ancient artifacts have advanced and adapted over the years, it is this adaptability that best exemplifies the success of the human organism. Recent advances in earthen buildings - the addition of cementitious binders, steel and fiber reinforcement, and engineering modeling, to name a few - have allowed a recent resurgence in this ancient building material to grace even the most contemporary structures in the Americas. This assertion is not to posit that all future buildings should be made of earth, however the re-imagining of archaic building materials in new and innovative ways can benefit from being more sustainability derived, locally sourced and emergent from existing ecologies.
Historical limitations of site-based materials and methods have long since departed as the solitary means of sourcing local materials for architectural design. With the relative ease of transporting and advance of industrial capabilities, globalization has led to homogeneity amongst architectural products in the Americas - often at the expense of local cultures. With the passage of time come rapid technological advances, leading to speculation that the design problem is no longer 'how', but ' $w h y$ '. Why build out of industrialized, nonlocally derived materials if they further seperate humans from their environment? How can we learn from historical building practices used by the indigenous cultures in order better understand existing ecologies? Can we couple innovative practices with historic patterns? If the architectural intervention lies solely on short-term benefits [or cost] without being cognizant to the longer-term realities of climatic, environmental and cultural - then we are truly only concerned with object-centric thinking.

With the imminent collision of a growing population - projected to reach 10 billion in the year 2056 - and escalating material expectations with a limited ecological capacity, development must create more reciprocity with the existent world around us. ${ }^{2}$ We, as a civilization, must learn from existing patterns and networks in order to better comprehend how our actions and designs can engage more symbiotically within the diverse ecological systems across the globe. As rapid deforestation, rising global temperatures and rampant air and water pollution cause havoc throughout the world, a conscious effort to utilize local materials [whether that be refuse, dirt or other low-energy materials] in more resourceful ways is imperative. Design must become more ecologically sensitive - taking account of the existing patterns and interrelating both site and culture, "not just about how we make things, but how we can make things fit harmoniously within an ecological, cultural and moral context." ${ }^{3}$

\section{ECOLOGY}

Ecology was first coined by Ernst Haeckel in 1866 by combining the Greek words Oikos [household] and Logos [study] to describe the analysis of nature's home now describes the investigation of relationships of natural systems and the impacts of one system on another. Such breadth can be difficult to pin down. An ecological system begins with the soil beneath and moves upwards through the plants, animals 

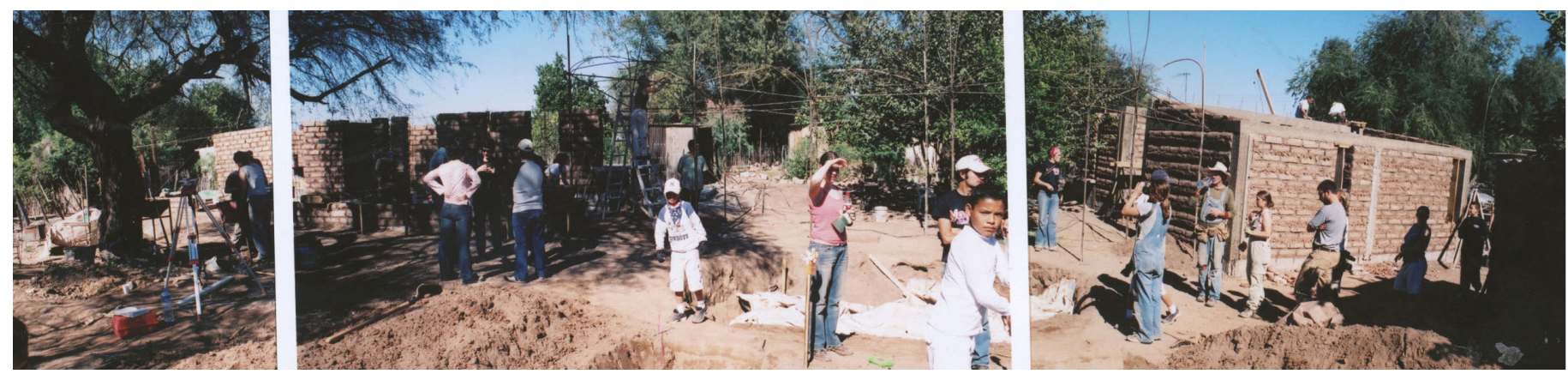

Figure 1: Multicultural collaboration and community building with the native ecological systems in the Sonoran desert, Mexico.

and people to create the entire bionetwork. Yet, the term ecology can also speak to the interrelationships embedded within each element. Ecological design envisions a future where each of these components can function in concert with the many disparate parts. Or, as David Orr points out; "ecological design is the careful meshing of human purposes with the larger patterns and flows of the natural world and the study of those patterns and flows to inform human actions" 4

Of course, not removing human beings from the ecological construct is key to finding viable architectural solutions. Once we treat human necessity and requirements separately from the surrounding biome, we cease to mesh with our surrounds, and create a reality that must replicate systems, patterns and connections that duplicate, or even combat with the existing systems. It becomes essential for ecological design to consider human existence as contextual - always nested within larger systems - no matter how small the interposition. Larger systems could be physical frameworks, but it is through the understanding these networks in relation to time, that they come alive. Seasonal changes, daily patterns and longer life cycles can be studied relative their impact on local, regional or global systems. Deep ecology prompts for a paradigmatic shift towards a "holistic world view" to recognize the "fundamental interdependence of all phenomena... embedded in (and ultimately dependent on) the cyclical process of nature." 5

How can architectural design work with existing ecosystematic elements to engage with diverse types of plants and animals? With the inherent abstractness of the term 'ecology,' it is important to delve into specific situations to determine how architectonic solutions might be best employed. Thorough investigation of the ecology of a precise place can provide a contextual understanding of the cultural and biological diversity to ensure designs respect the larger social and cultural patterns and preserve the essence of the local. John Todd poetically points out this need for ecological design to create "elegant solutions predicated on the uniqueness of place" ${ }^{6}$

\section{MATERIALS AND ECOLOGICAL RESONANCE}

By removing the abstract, materials are investigated and employed for their ecological resonance. Not only are materials the physical manifestation of spatial constructs, but each holds its own ecological stamp, a story of embodied energy, locale and history. Paul Oliver points out that it is absolutely fundamental that architecture expresses local culture, which can be read as the vernacular - tuned to place, climatically and ecologically imbedded - and that failure of much of architecture is that many architects are only interested in "architecture as some abstraction, separate in a sense from the values or the qualities that the peoples of the various cultures require in their building." 7 Materials have an intrinsic and direct connection to architectural positioning within local environs. In his seminal book, "Dwellings", Oliver investigates the architecture of the common man, documenting vernacular architectural solutions across the world drawing connections from materials, climate and culture to inspect how "90 percent of the world's buildings" are built and lived. ${ }^{8}$ These dwellings tend to blur geo-political borders and align more so with ecological zones or regions. In this sense, the architectural solutions are less stylistically derived, and more a function of locale, technology and designing with natural systems already present. There is an evident and pronounced interrelation of site and culture, as well as social equity and community exemplified within the projects presented in the book. Out of necessity, Oliver presents solutions are very much tuned to the site, temporality and ecology.

\section{THREE INTERVENTIONS}

Taking cues from this material and cultural resonance through the thorough understanding of the underlying ecology, the three projects exhibited within this paper build on embedded knowledge within the existing ecology in innovative ways. Local needs, materials and techniques are combined with a broadened perspective and understanding of the ability for these native projects to speak to global issues.

Each are designed as open-air, wilderness structures, where nature becomes an active participant in the spatial definition of the place. The scale of each is small - ranging from single-family houses to pavilions as a way to test material strategies at full-scale and receive almost immediate feedback. By embracing the existing climates and designing with emphasis on the limitations and constraints these projects tap into passive design strategies to create thermal comfort microclimates for their occupants. The materials chosen are directly derived from the local ecologies - earthen blocks, local woods, reimagined resources that have been discarded or underutilized ensure a direct and temporal connection to the site. Daylight, sun path and winds are tracked, and the the passing of time, day, season, year is marked and celebrated through the designs to demonstrate an 
integral relationship of site and material is forged, to galvanize locale with place.

This situated-ness is the thrust of the three projects described within this paper. Each designed within [and for] and different culture, place, climate and season. Each attempts to emanate from and merge with the existing ecologies as a way coexist within the larger framework - not as object-centric units that clashes with the natural patterns but take cues and connect to the surrounding natural systems. These solutions investigate unique environmental foci in the hopes of transferring knowledge of how ecology, architectural design and material construction may deal with the abstract nature of ecology on real terms.

The first, Hogar del Viento y Sol, a small design/build effort that combined local masons and community with architecture students, professors and artists to create a residential compound for the Yaqui Indians in the Sonoran Desert, Mexico. Integrating local, adobe infill walls with North American engineering of reinforced concrete pier and beam construction to create a more resilient structure - tuned to place. The second is an Ice Hut, designed as a Warming Hut in Winnepeg, Canada. And lastly, Sukkah Shalom, designed and built with the local Jewish Community Center that used a rope enclosure and recycled wood to create a place of reflection. The agency of the environment within each design is crucial as local techniques and materials are utilized to embed people within an existing ecological system. Not only to create an object within a context, but an object that emerges from the very fabric of the place. These designs are meant to provoke our preconceived notions of living, while illuminating the importance of preserving native cultures.

\section{HOGAR DEL VIENTO Y SOL}

Situated within the Sonoran desert of northwestern Mexico, the prompt was for the design of two low-income homes for the Yaqui Indians - native people to the area. Material investigation looked at the desert region, with high diurnal temperature swings, low humidity, a short rainy season and no record of seismic activity, to determine that the primary building material should be earthen adobe blocks. Working with indigenous Yaqui craftsmen familiar with this vernacular building technique was essential to creating a cross-border interchange with the local community to tune global perspectives to the specific cultural and biological ecologies existing within the place. Upon determining that typical adobe structures in the area were unreinforced, a strategy was derived to incorporate the high-mass walls of traditional adobe blocks made of local land and labor with the benefits of modern structural engineering in a reinforced concrete framework.

The two homes utilized passive ventilation strategies to capture prevailing winds of the region, while shading the structures from the sunlight during the summer months and allowing the sun to warm the structures [and hold the warmth within the walls] during the winter months. Light, tectonic frames were used in creating these more permeable filters for light and air. These tectonic elements were found in the local bamboo grass called carrizo, which were used to

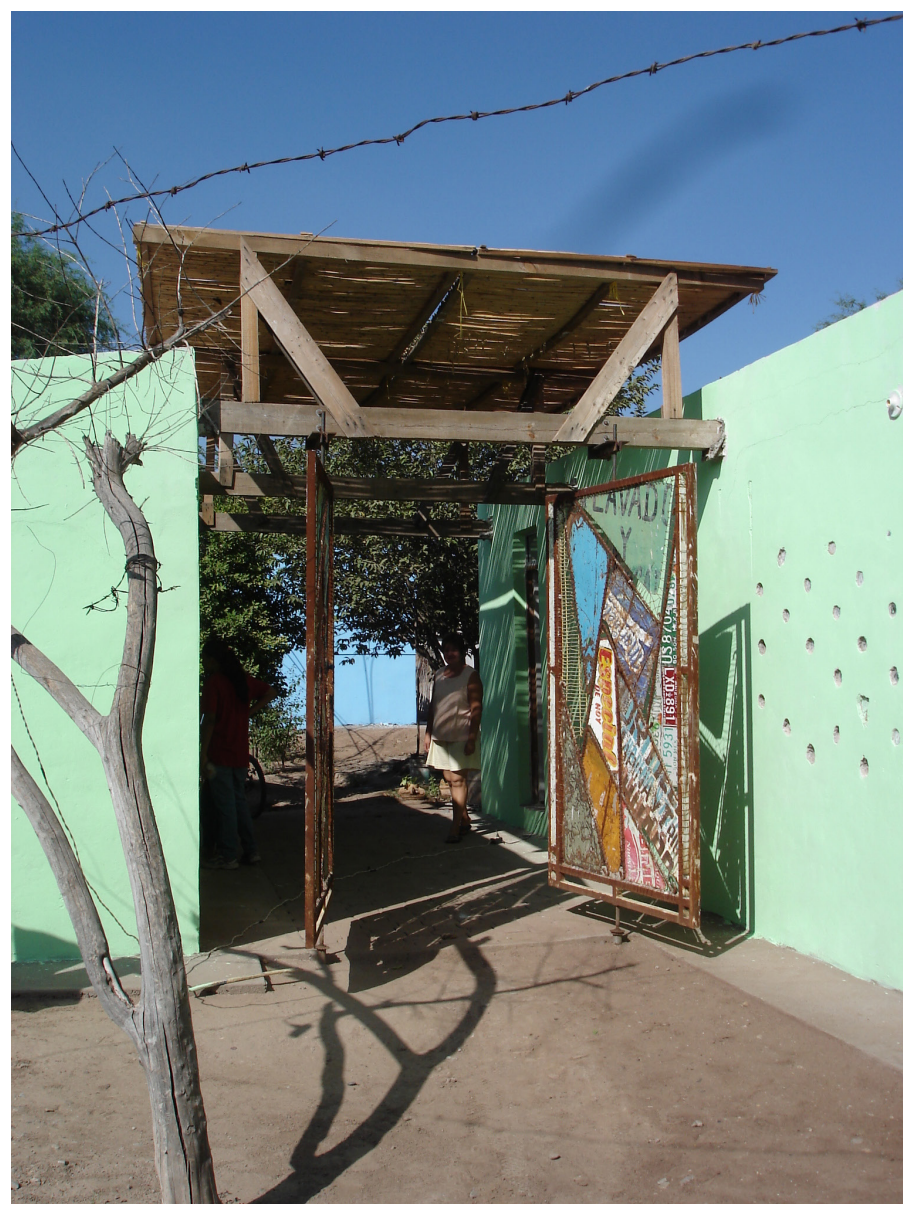

Figure 2: Entry utilizing re-used metal collected from local landfill, native carrizo shade structure and earthen adobe walls. Mexico.

roof the structures inside and out, while more decorative elements - reused glass bottles for window walls and disused metal signage was collected from the local landfill and employed to create the entrance gate. Initially the clients were suspect of using 'trash' for their front door, and wanted to conceal any evidence of it with a layer of paint, but the decorative element quickly became a point of pride in showcasing the innovative nature of their collaboratively designed dwelling.

Re-use and adaptive material choices did not stop there. Selfsustaining measures employed on the site were the use of a large cistern to collect what water fell on the desert - typically coming all at once - throughout the year. Composting toilets were used to generate organic material re-used for the garden that was nestled in the area between the two houses. These houses became a showpiece for the local government, and Provay - a local non-profit organization providing much of the low-income housing for the Yaqui Indians of the region that we partnered with in the design and construction process. The use of locally-derived and ecologically tuned buildings reconciling people with the landscape are more closely aligned with the ideals of indigenous civilizations more harmonious connections with nature. These differed greatly from what Provay had been building at the time - cinderblock homes with no insulation, limited ventilation or light - that required active air-conditioning to be comfortable, and at 


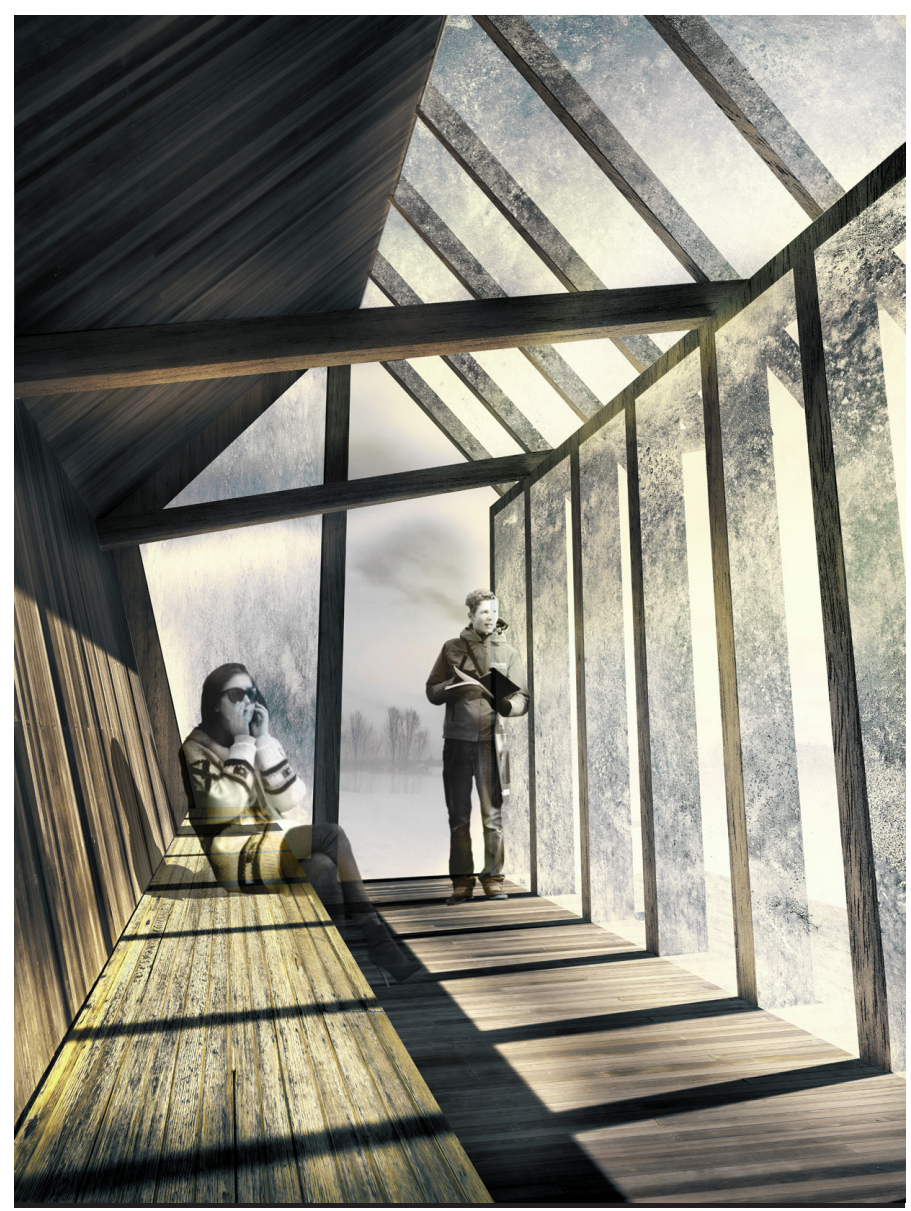

Figure 3: Day rendering of the Ice Hut interior, Winnipeg, Manitoba.

roughly the same cost. This collaboration of engineers, architects and students along with local craftsmen, people and government created positive impact for the family immediately affected, while also bringing notions of ecology, local tradition and culture to the forefront of conversation for all future houses. Sometimes it takes the eyes of an outsider to see the intrinsic beauty existing within another's culture, but the north/south exchange of knowledge was likely more significant to the students from Texas who learned how people of another place inhabit their world and live within nature.

\section{ICE HUT}

In the second project, a competition entry was designed in conjunction with the annual Warming Huts Competition in Winnipeg, Manitoba, at the confluence of the Assiniboine and Red Rivers. Fondly known as "The Forks", these rivers have been the veritable lifeblood of the city for centuries, and the reason that indigenous peoples, traders and eventual settlers selected this location for the future provincial capitol. During the winter months, this essential waterway literally changes state, freezing over to create a linear park for the community to celebrate the changing of the seasons.

Considering the temporal importance of this event, inherent within the river's phase-change - from the flowing, nebulous body of water that bisects the city, to the frozen, fixed solid, that bridges the city during the winter months - the beauty of this simple yet phenomenal was an exciting opportunity. From the onset, this temporary structure endeavored to embody this temporality by literally using the very essence of the event - water/ice - within its architectural solution. Looking to north, native Inuit peoples have been creating dwelling structures out of ice for millennia. Combining this vernacular solution with something more grounded in the ecological diversity within the southern areas of Canada, where the site was located. Canada's boreal region covers almost 60 percent of the country's land area, spanning from the Atlantic to the Pacific, and includes approximately one third of the circumpolar forest that rings the Northern hemisphere. ${ }^{9}$ This project sought to marry the temporary and the permanent, by utilizing these native, site-specific materials in the creation of a warming hut.

The multi-disciplinary team consisted of local woodworker/furniture maker, a visual artist, along with designer/architects and several college students to design the final entry. The shape/form was derived from the movement/flow of the skaters, and the resting profile of a seated human, coupled with linear views of the coming and going along the river. The structure was envisioned to collect and diffuse the low sun angles of the winter months through stacked translucency of ice blocks, which would be supported with a heavy timber wooden lattice.

Material studies were developed to determine different levels of opacity created through both the type/purity of water, along with the temperature/speed of the freezing process. Using pure water, and rapid decreasing of temperature from boiling to freezing was found to be the most promising for visual acuity. Over time, as the solar aspect and temperature level moves higher, the blocks would register this passage of time through progressive melting and shrinkage of the iced veil. As the seasons changed, the sun climbed, and the weather warmed, the frozen structure would eventually melt back into the waterway below, while the wood armature would be salvaged for a second life as an open-air summer pavilion.

\section{SUKKAH SHALOM}

In the third example, a small group of architecture students, professors and volunteers from the local community were united in the design and construction of a cultural artifact that reflected upon the phenomenological connection humans have with their most immediate environs through the construction of a wilderness structure. This structure, one of the winning entries for the Sukkah City: Austin competition, was designed and built by community members in a celebration of Jewish faith. By reinterpreting the tectonic qualities of earthbound materials [wood, rope, and metal], and removing these natural elements from the ground and in an open design that hovers just above the ground, the architecture reifies the person's relationship with the natural space he or she occupies in the world.

During the weeklong festival of Sukkot, the Jewish faith celebrates the culturally significant event of their fall harvest, and connection to their history and environs through the building of a temporary shelter, called a Sukkah. The Book of Leviticus describes the structure 


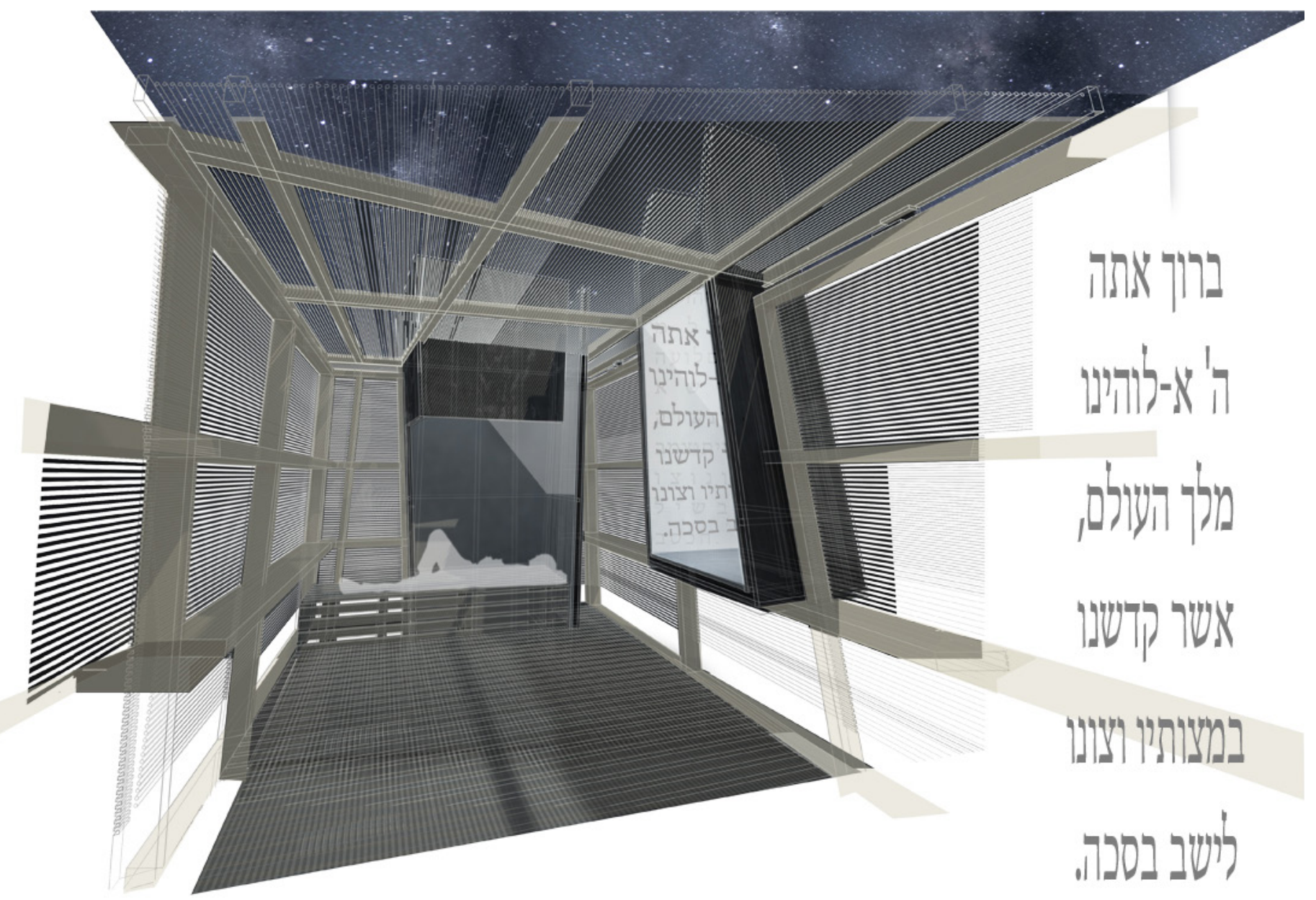

Figure 4: Rendering of Sukkah Shalom illustrating the connection of the architectural intervention with the night sky.

as a "wilderness structure" which embodies the Israelites time of wandering through the desert after they were freed from their slavery in Egypt. Specific architectural guidelines are outlined in the Talmud [a central text of Judaism] in which the architectural experience becomes center point to the celebration by ensuring a certain phenomenological atmosphere is created for this temporal event. Even today, these ancient texts remain significant in the presentday re-creation of these religiously significant architectural works - embodied through the materiality, configuration and relative openness of the structure. Also embedded within the Ancient text is the importance of constructing by hand. By using readily available materials from the fall harvest, people of the Jewish faith are presented with a haptic understanding of the world around them through the physical construction of the structure - connecting the earthly endeavors toils of the fall harvest to the design of the sukkah.

Upon entering the sukkah, the connection with ones surrounds invites a reinterpretation through a hemp rope filigree matrix, held in place by a lightweight structural wood frame. This combination of wood and rope present at once a sense of protection and security, while still being physically engaged with the nature enveloping the thin membrane of rope and wood lattice. This thin transparency is punctuated by a series of wooden apertures that create three distinct moments for reflection, marked not only by their potential for resting, reading, eating, reflection and prayer, but each is mapped with the solar angles on the seven day festival of sukkot, situated within Austin, Texas. It is within this sukkah that ones connection to natural is reinforced through the constant temporal reminder as these simple materials are animated by the interplay of sunlight during the day, and moonlight at night. The rope thatch is completely open to wind and rain, day and night. This openness reminds the occupant that spirituality is open to others, and that our life should be connected to natural elements and surroundings.

\section{CONCLUSION}

Architecture, at its most meaningful, is the physical embodiment of culture. Without an understanding of ecology, we cannot possibly design with any relevance to place or with the future in mind. Each of the three projects mentioned above investigates natural systems through the adapting, reusing and reimagining of existing relationships. While the scale of each of the projects are chosen for the immediacy of testing ideas, connections and the material resonance with in a specific site as much to exhibit a different mode of thinking about architecture as to question how persons can mesh with their environs in a more inclusive manner. Large-scale transformations will likely require a more expansive dialogue regarding culture and 


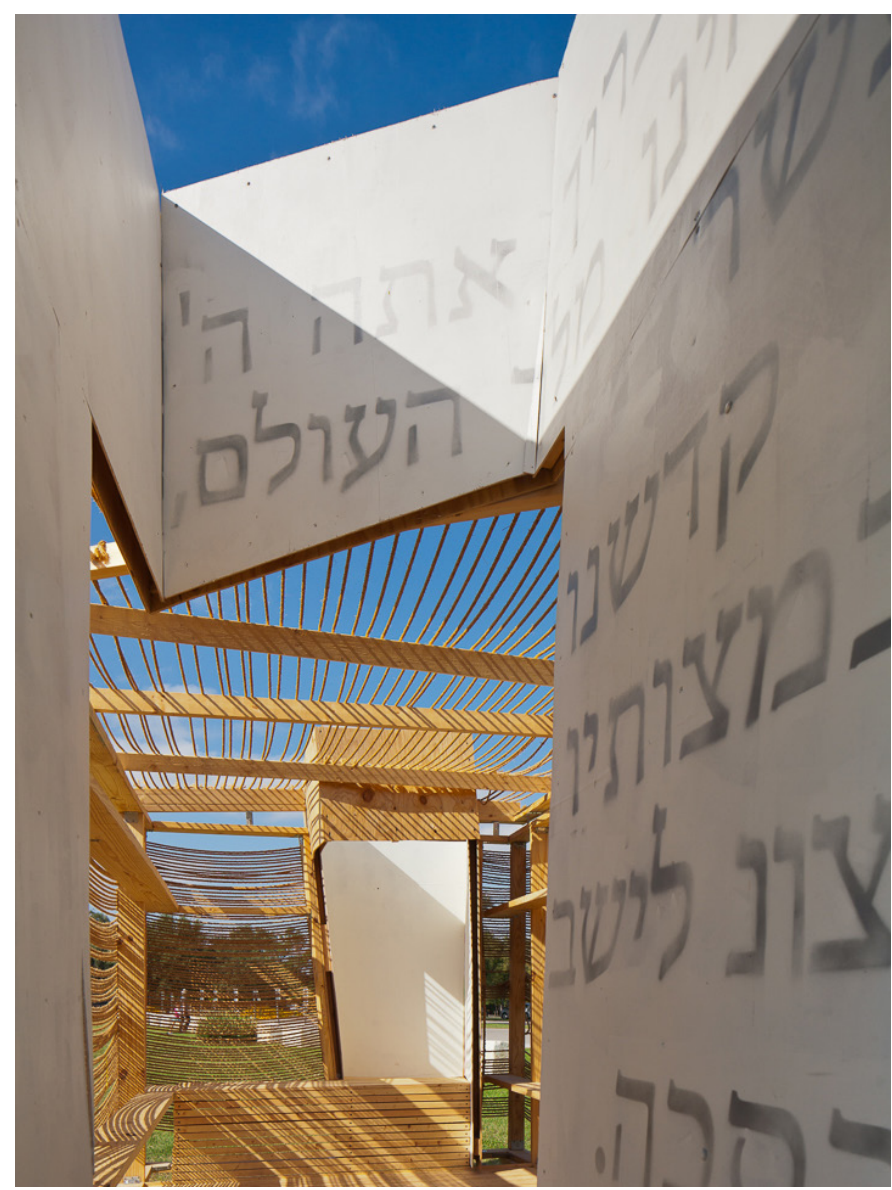

Figure 5: Entry threshold moment displaying the ceremonial prayer of Sukkot. Sukkah Shalom, Austin, Texas. Photo credit: Patrick Wong

historical heritage in addition to underlying ecological systems. ${ }^{10}$ As we are all living on one planet, with a finite amount of resources water, materials, and energy - we must think more long-term to our solutions and how these impact future generations.

We, as a modern society have become more isolated and less concerned with the long-view of ecological systems or community. While each of these projects attempted to ask bigger questions about biological and cultural ecologies, in order to illuminate alternative solutions and generate public discourse on the gravity of the matter much more has to be done - and at larger scales.

Thomas Berry ruminates on the extent of problem facing society in stating that our challenge "is to transcend not only national limitations, but even our species isolation, to enter into the larger community of living species...to bring about a completely new sense of reality and value." 11

These are tall tasks, especially for architectural designers, but each intervention should begin with an understanding of existing ecological systems and patterns to ensure innovative solutions representative of the larger frameworks of the local, region and globe.

\section{ENDNOTES}

1. Cassell, Robert O. "A Traditional Research Paper: Rammed Earth Construction". Ashland Community and Technical College. December 17, 2001. Retrieved January 12, 2016.

2. The United Nations Population Division of the Department of Economic and Social Affairs every two years calculates, updates, and publishes estimates of total population in its World Population Prospects series. These population estimates and projections provide the standard and consistent set of population figures that are used throughout the United Nations system.

3. Orr, David. "Architecture, Ecological Design and Human Ecology." Part 1 In The Green Braid. (New York: Taylor and Francis, 2007) p. 31

4. Orr, David. "Architecture, Ecological Design and Human Ecology." Part 1 In The Green Braid. (New York: Taylor and Francis, 2007) p.21

5. Capra, Fritjof and Gunter A. Pauli. "Steering Business Toward Sustainability" (United Nations University Press, 1995) p.21

6. Todd, J. and N. Todd, From Eco-Cities to Living Machines: Principles of Ecological Design (Berkeley, CA: North Atlantic Books, 1998).

7. Oliver, Paul. "International Dialogues," lecture at Oxford Brookes 2010.

8. Oliver, Paul. "Dwellings: The Vernacular House Worldwide." Phaidon Press, 2003.

9. Canadian Boreal Initiative Online, (http://www.borealcanada.ca/boreal-did-youknow-e.php); State of Canada's Forests: 2004-2005, accessed June 10, 2016.

10. David, Orr, "Listening to the Land: Conversations about Nature, Culture and Eros." Edited by Derrick Jensen, [Chelsea Green Publishing, White River Junction, VT, Printed in The United States, 2004], p. 33

11. Berry, Thomas, "The Ecological Age" [Counterpoint Publishing, 2006], p. 42 